This item was submitted to Loughborough's Research Repository by the author.

Items in Figshare are protected by copyright, with all rights reserved, unless otherwise indicated.

\title{
Understanding email interaction increases organizational productivity.
}

PLEASE CITE THE PUBLISHED VERSION

PUBLISHER

(c) ACM

LICENCE

CC BY-NC-ND 4.0

\section{REPOSITORY RECORD}

Jackson, Thomas, Ray Dawson, and Darren Wilson. 2019. "Understanding Email Interaction Increases Organizational Productivity.”. figshare. https://hdl.handle.net/2134/485. 
This item was submitted to Loughborough's Institutional Repository by the author and is made available under the following Creative Commons Licence conditions.

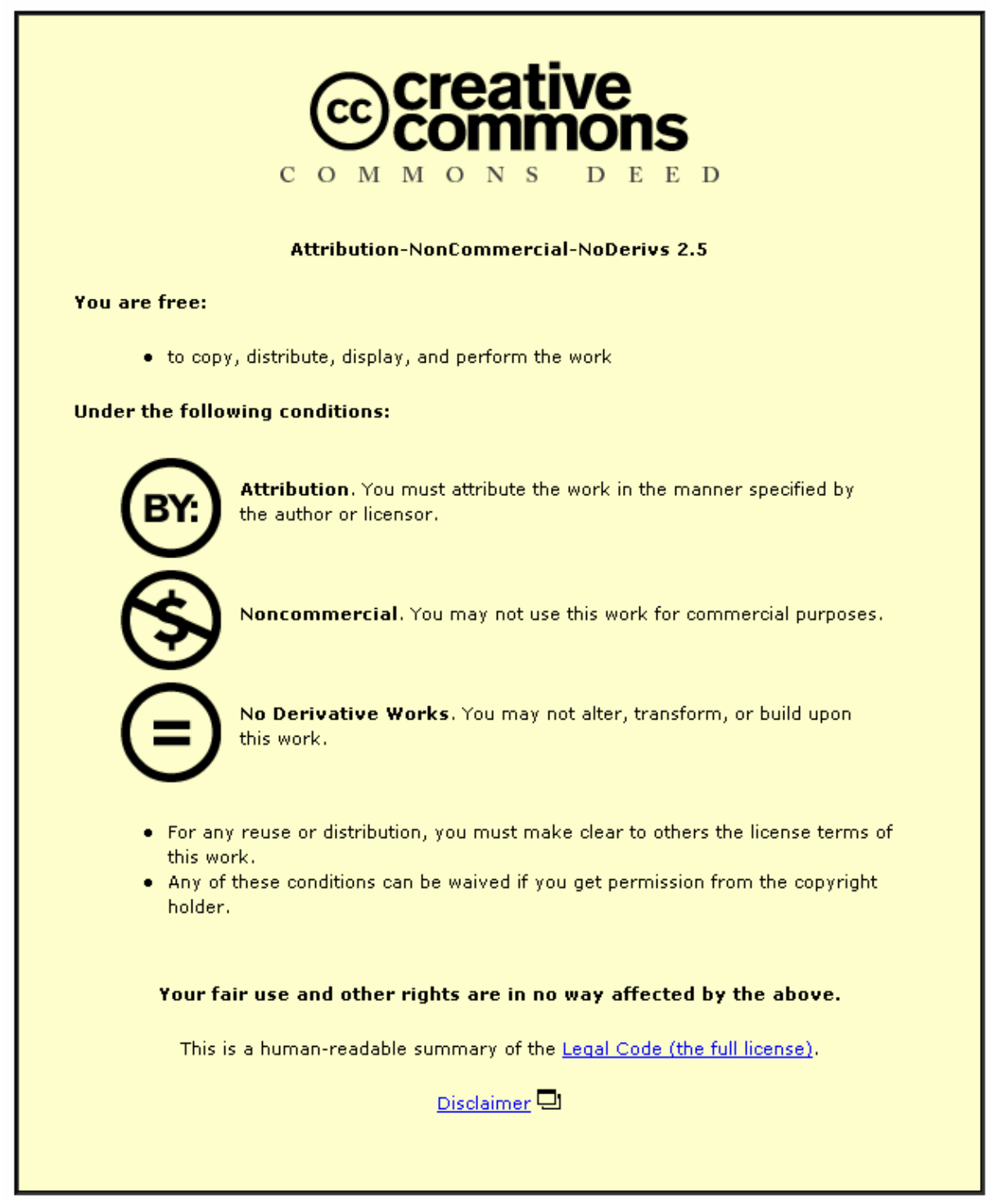

For the full text of this licence, please go to: http://creativecommons.org/licenses/by-nc-nd/2.5/ 


\section{Understanding Email Interaction Increases Organizational Productivity - Dr. Tom Jackson, Loughborough University}

\section{Introduction}

Electronic communication is becoming an integral part of the communication structure within organisations, but the costs and benefits are not being assessed. The aim of this research was to analyse the cost effectiveness of using email, to suggest ways in which the cost effectiveness can be improved, and to discover if there is an interrupt recovery time associated with an email interruption. This research was mainly carried out at the Danwood Group which has just over 500 employees at 19 sites around the UK. The Danwood Group retails office equipment, predominately photocopiers.

As part of trying to understand email interactivity, research has been carried out to determine if there is such a phenomenon as an interrupt recovery time for email and, if there is, to discover if there is a "hard" cost associated with an email interruption. DeMarco reported that the recovery time after a phone call interruption is at least 15 minutes, thus increasing the amount of time spent on interrupts a day (DeMarco T. and Lister T. 1987). However, DeMarco’s research was carried out using software developers as the subjects. The highly creative nature of a software developer's job means they are likely to require extra time to recover from an interrupt compared to other job roles, hence the 15 minutes recovery time. So far, there has been no reported empirical research into how long it takes to recover from an email interrupt.

\section{Recording Email Interactivity}

A number of different applications were reviewed to find the most appropriate to record email interactivity. These included, Windows Virtual Network Computing (WinVNC), Lotus SmartCAM, I-SPY and Windows Ranger (Richardson Tristan 1998), (Lotus 2000), (Visionsoft 2000), (Sentinel 2000). Many had a number of restrictions, such as, lack of reliability, no access to the monitoring source code, inappropriate system tray icons, too slow or excessive amounts of media required to record an employee at work for a full day. It was decided that WinVNC would be used alongside a video recorder to record employee activities throughout the day. 
WinVNC is a remote display system that allows viewing of a remote computer 'desktop' environment, not only on the machine where it is running but also from anywhere on the Internet and from a wide variety of machine architectures (Cambridge 2000). WinVNC was set-up on both the client and server side to allow monitoring of the employee's machines remotely. The original WinVNC program was modified slightly by one of the authors to remove the icon shown in Figure 1 from the system tray. With the icon removed the employees would not know when they were being monitored. The server side had a video recorder attached to the computer, to record all the employees' activities on the screen to videotape. A total of 16 employees were monitored over 28 working days, which led to over 180 hours of videotape recordings.

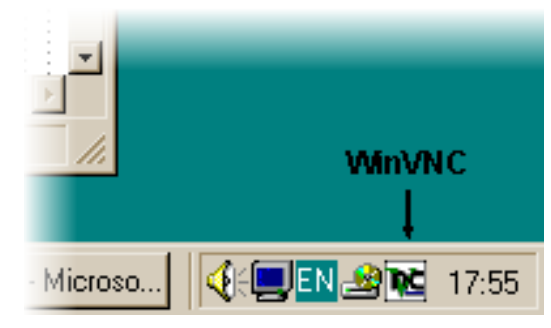

Figure 1 - Shows the WinVNC icon that was later removed from the system tray

At the same time individual employees were being monitored, every employee using email at the Danwood Group was also being monitored for the frequency of individual email collections from the server.

\section{Data Analysis}

All the employees' email interactivity was recorded and analysed as well as the activities leading up to and after the email interruption. The definition of an email interrupt is "any email distraction that makes employees stop their planned activity". The recovery time was calculated by recording the amount of time that it took employees to return to their work at the same work rate at which they left it. This required an element of judgement by the person reviewing the recorded material. However, in nearly every case there was a clear point where the user ceased to move the mouse around the screen and jump between screens trying to pick up their train of 
thought and the production of useful work. Although this may be regarded as a rather inexact measure, the clear change as the user starts productive work means that, in practice, interpretation of the activities by different people would not have given any significant difference in the results.

Out of the employees monitored 70\% used Microsoft Outlook 2000 and 30\% used Microsoft Outlook 97. All the employees had a new "email arrived" icon appear in the system tray when new email arrived and 57\% of the employees also had a new “email arrived” pop-up dialogue box appear.

It took the employees an average of 1 minute 44 seconds to react to a new email notification by opening up the email application. The majority of emails, 70\%, were reacted to within 6 seconds of them arriving and 85\% were reacted to within 2 minutes of arriving. The time it takes the employees to recover from an email interrupt, and to return to their work at the same work rate at which they left it, was found to be on average 64 seconds.

It appears that there is a clear communication pattern for email and figure 2 shows the interaction time on the email system throughout the day. The graph measures email interactivity, where email interactivity is classed as a user reading or composing a message including reply, reply to all and forwarding. There are two main peaks, one at 8:30am, which is due to employees coming into work and checking for new email, and one at $16: 30 \mathrm{pm}$, which is due to the employees checking their email before they go home. In total there are four natural communication periods during the day, the other smaller peaks in Figure 2 are at 11:30am and at 14:30. These smaller peaks could be employees checking their email just before and after their lunch. 


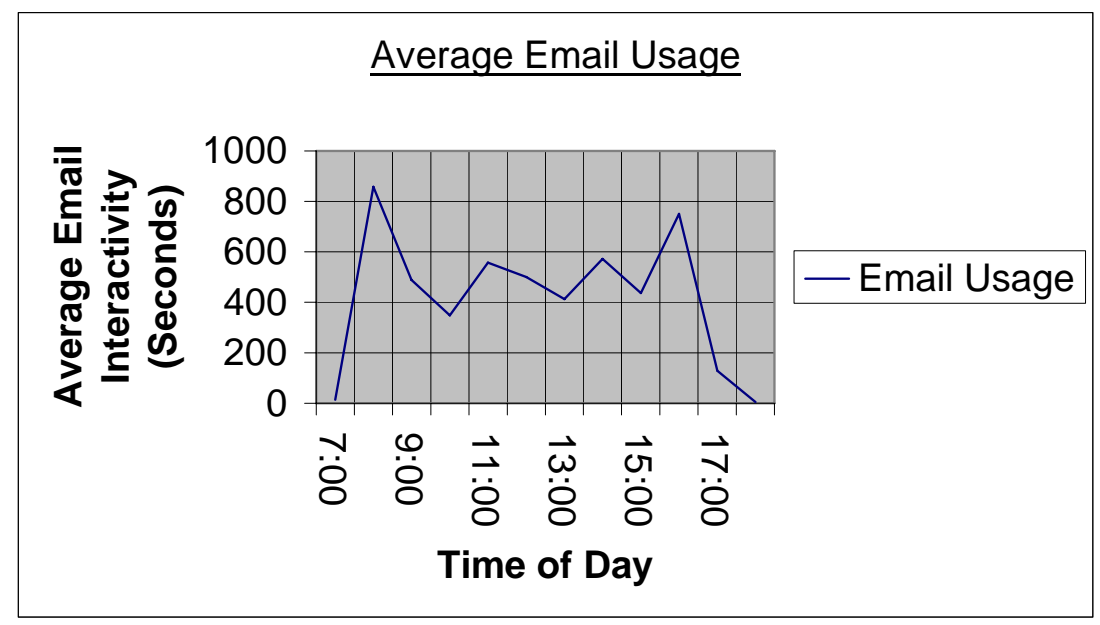

Figure 2 - Email usage throughout the day

Communication patterns require further research to try and establish how to increase employee effectiveness by finding the best time to communicate during the day to keep interrupts to a minimum. However, companies could experiment and encourage the majority of communication to take part during four identified natural peaks in this research to help reduce employee interrupts and to reduce the risk of message fatigue.

\section{Summary}

This research has found that the interrupt effect from emails is more than might be believed. Employees at the company studied allowed themselves to be interrupted almost as frequently (every 5 minutes) as with telephone calls. The common reaction to the arrival of an email is not to delay the response to a time that is more convenient to the user but to react within 6 seconds, again almost as quickly as they would respond to telephone calls. This means the interrupt effect is comparable with that of a telephone call. The recovery time from an email interruption is, at 64 seconds, significantly less than some published recovery times for telephone calls. While this gives a significant reduction in recovery time, with users receiving more and more emails the cumulative effect is still likely to be significant. It is to be concluded, therefore, that while email is still less disruptive than the telephone, the way the majority of users handle their incoming email has been shown to cause far more interruption than expected.

By analysing the data captured from the employees interacting with the email application and how they dealt with the frequency of interrupts, the author has been 
able to create a set of recommended guidelines for email usage within the workplace that will increase employee effectiveness.

- Reduce the prominence of interruptions through turning off the new email alert dialogue box and email sound alerts.

- Restrict the use of email-to-all messages, and in particular reply-to-all messages. The use of more targeted email user groups may assist in this respect.

- Set up the email application to display in the inbox the sender, the subject and three lines of the email, so that the recipient can quickly determine if the email requires immediate attention.

- Set up the email application to check for email at no less than every 45 minutes.

- Introduce training to all staff on how to use email in areas such as setting email priority, email housekeeping with message rules, effective use of user groups and address books, and constructing better structured emails.

By taking a "typical" employee and making some hypothetical assumptions it is possible to determine the amount of time that can be saved through implementing the guidelines mentioned above. If an employee has set up the email application to check for email every 5 minutes then it is possible, if (s)he is a heavy user of email, that there could be 96 interruptions in a normal 8-hour working day. However, if the email application was set up to check for email every 45 minutes then the amount of possible interruptions is reduced to 11 per day. For example, if it takes on average 1.5 minutes to read and recover from an email and the employee is interrupted every 5 minutes, then this would only leave the employee 3.5 minutes before the next interrupt. However, if the employee was interrupted every 45 minutes and the emails had accumulated to a total of 9 , then it would take on average 6 minutes to read all 9 emails and recover from the interruption. This would then leave 39 minutes before the next interruption, allowing the employee more time to get on with "real” work.

Disruption can also be minimised by reducing prominent "new email” alerts. Through turning off "new email” pop-up dialogue boxes and sound alerts, and by just having a 
"new email" icon appear in the system tray, a user will be less aware that an email has arrived. This is useful as, if the employee is in the midst of concentration, a prominent interruption will break their thought processes. By only having the new email icon in the system tray, employees' attention would only be attracted when their concentration levels are not so high and the interrupt would occur at a more convenient time.

It would be beneficial to the majority of employees to restrict the use of the email function "reply-to-all". For example, if the reply-to-all function is used on an email containing 120 recipients it could collectively cost the company 3 hours of employee time in being interrupted and viewing the email.

Throughout the study some employees had developed their own ways of dealing with new emails. A number of employees had set up their email application to display three lines of the email subject, the sender and date within their inbox. This was thought to save them time, as they would quickly scan the new email in the inbox and determine if it was important. If it was important they opened the email, or otherwise they left it to a more convenient time to read it.

This research has shown the value of measuring communication processes. The analysis of email has enabled the effect on employee time to be quantified and has given some surprising results. This has led to a series of recommendations that will enable the Danwood Group to make better use of email communication and increase employee effectiveness. The implication for managers in other companies is that if their own employees have similar practices in using email then the companies would also benefit from following these recommendations.

Cambridge, AT\&T Laboratories. 2000. “Windows Virtual Network Computing.” . http://www.cam-orl.co.uk/vnc/winvnc.html: AT\&T Laboratories Cambridge.

DeMarco T., and Lister T. 1987. Peopleware: Productive Projects and Teams. New York: Dorset House.

DeMarco T., and Lister T. 1999. Peopleware. Productive Projects and Teams 2nd Ed. New York: Dorset House Publishing Company. 
Lotus. 2000. “Lotus ScreenCam.” .

http://www.lotus.com/home.nsf/welcome/screencam/: Lotus.

Richardson Tristan, Stafford-Fraser Quentin, Wood Kenneth R., Hopper Andy. 1998.

“Virtual Network Computing.” IEEE Internet Computing 2:33-38.

Sentinel. 2000. “Windows Ranger.” .

http://www.rangersuite.com/products/win_ranger/winr_functions.htm:

Sentinel Products.

Visionsoft. 2000. “I-SPY.” . http://www.visionsoft.com/products/ispy.htm:

Visionsoft. 